\title{
Observed Change in Sahel Rainfall, Circulations, African Easterly Waves, and Atlantic Hurricanes Since 1979
}

\author{
Shih-Yu Wang ${ }^{1,2}$ and Robert R. Gillies ${ }^{1,2}$ \\ ${ }^{1}$ Utah Climate Center, Utah State University, Logan, UT 84322, USA \\ ${ }^{2}$ Department of Plants, Soils, and Climate, Utah State University, Logan, UT 84322, USA
}

Correspondence should be addressed to Shih-Yu Wang, simon.wang@usu.edu

Received 1 April 2011; Revised 1 August 2011; Accepted 26 August 2011

Academic Editor: Amadou Gaye

Copyright (C) 2011 S.-Y. Wang and R. R. Gillies. This is an open access article distributed under the Creative Commons Attribution License, which permits unrestricted use, distribution, and reproduction in any medium, provided the original work is properly cited.

\begin{abstract}
Here, we examine the dynamic properties associated with the recent increase in the Sahel rainfall using an ensemble of five global reanalysis datasets (1979-2010). The rainfall that has been observed to be increasing over the Sahel is accounted for by enhancements in both the tropical easterly jet and the African easterly jet, both of which are known to induce wet anomalies. Moreover, positional shifts in the African easterly jet and African easterly waves (AEWs) accompanied the northward migration of the Sahel rainband. Change in the African easterly jet and AEWs are coupled to a northward shift and amplification of convective activity; this signals an increased potential for the occurrence of flash floods along the northern Sahel. In addition, the result from a wave tracking analysis suggests that the change in AEWs is closely linked to increased activity of intense hurricanes in the North Atlantic. The synoptic concurrence of AEWs in driving the dynamics of the Sahel greening and the increase in tropical cyclogeneses over the North Atlantic is an important aspect in the evaluation of climate model projections.
\end{abstract}

\section{Introduction}

Beginning around the early 1980s, the Sahel belt of Africa has undergone a continual increase in both precipitation and vegetation greening $[1,2]$. This so-called Sahel greening has been a signal of a gradual recovery from very dry conditions in the 1980s [3] and from the days of prolonged droughts and famines during the late 1960s mid-1990s [4, 5]. The increase in Sahel rainfall has been attributed to a combination of factors such as global warming [6, 7], decadal-scale variability in the global sea surface temperature (SST) [8-11], and greening-associated changes in the carbon cycle [12]. Previous studies have pointed to a robust connection between the low-frequency rainfall variability in the Sahel and the interdecadal SST variations over the tropical Pacific $[6,13]$, as well as in the Indian Ocean $[11,14]$. Recent evidence has suggested an even closer relationship between the Sahel rainfall and the Atlantic Multidecadal Oscillation (AMO) —a basinscale pattern of SST variability driven by Atlantic meridional overturning [15]. For instance, the 1980-onward increase of the Sahel rainfall happens to coincide with the warming phase of the AMO - a process known to shift the intertropical convergence zone (ITCZ) poleward $[10,16,17]$. As shown in Figure 1, the summer precipitation differences between 1995-2009 and 1979-1994 illustrates the northward displacement of the oceanic ITCZ that is connected to the expansion of the wetness domain along the Sahel.

Precipitation in the Sahel is produced through a set of complex interactions between different circulation systems - in particular, the tropical easterly jet (TEJ) in the upper troposphere that extends from South Asia, the African easterly jet (AEJ) in the middle troposphere $(\sim$ $600 \mathrm{mb}$ ), and the tropical monsoon westerly in the lower troposphere that lies beneath the TEJ; these circulation features are depicted in Figure 1. Situated north of these circulation features is the shallow Sahara heat low that produces strong meridional gradients in heat, moisture, and potential vorticity - these lead to mixed barotropic-baroclinic instabilities conducive to the development of African easterly waves (AEWs) [18-20]. About 90\% of the region's seasonal rainfall is generated by organized convective systems [21]; such convective systems are frequently initiated by AEWs 


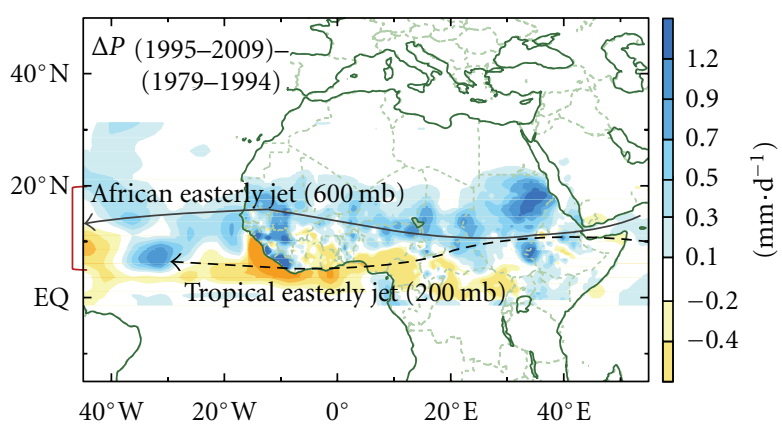

Figure 1: July-August precipitation differences between the periods 1995-2009 and 1979-1994, from the University of Delaware data over land and the GPCP data over ocean. Jet cores along the African Easterly Jet and the Tropical Easterly Jet are indicated. The tropical monsoon westerly lies underneath the TEJ. The left bracket in red outlines the latitude zone used in Figures 2-6.

along and to the south of the AEJ [22]. Chen and Wang [23] have estimated that about $50 \%$ of the June-September rainfall in West Africa occurs under the influence of AEWs. Moreover, AEWs also spawn tropical cyclones over the North Atlantic [24, 25], and AEWs are recognized as important precursors to intense hurricanes of Category 3 or above [26$28]$. Recent studies $[3,29]$ have found a positively correlated, yet fluctuating relationship between the tropical cyclone activity, the West African monsoon, and AEWs.

When it comes to delineating changes in the Sahel's climate, in particular those that may be attributed to climate change, a problem arises in that general circulation models (GCMs) are presently unable to simulate the aforementioned complex dynamics $[30,31]$. Such deficiencies have resulted in large spreads in the model projections [32]. It is therefore not surprising that previous studies that have focused on climate change in West Africa and the Sahel have seldom evaluated what changes have come about in the three jets (TEJ, AEJ, and the monsoon westerlies) and any associated feedback into the AEWs. In an attempt to bridge this gap, we decided to utilize an array of observation-based data to examine the synoptic environment associated with the observed precipitation change in the Sahel. Given the extent of our analysis, we were also able to investigate the extent of any downstream effects the Sahel climate change has had on the documented increase in tropical cyclone threat over the North Atlantic $[33,34]$. Precursors to the analysis were first the adoption of several precipitation datasets and different generation global reanalyses as described in Section 2. The analysis in Section 3 is followed by a discussion of the temporal-spatial evolutions of prescribed meteorological variables. Links to Atlantic tropical cyclones and associated large-scale circulations are discussed in Section 4. Concluding remarks are presented in Section 5.

\section{Data Sources}

Merged satellite- and gauge-derived precipitation data have consistent spatial and temporal coverage and have been useful in the study of African climate. Our study utilized three sets of precipitation data: the Climate Prediction Center (CPC) Merged Analysis of Precipitation (CMAP) [35], the Global Precipitation Climatology Project (GPCP) version 2 [36], and gauge-based precipitation compiled by the University of Delaware (UDel) [37]. For verification purposes, we adopted the uninterpolated version of outgoing longwave radiation (OLR) measured from polar orbiting satellites provided by the National Oceanic and Atmospheric Administration (NOAA). For sea surface temperatures, we utilized the NOAA Extended Reconstructed Sea Surface Temperature (SST) V3b [38]; for surface temperatures over land, we used the CRU Air Temperature Anomalies Version 3 [39] with the time period up to present.

Five global reanalysis datasets (hereafter referred to as reanalyses) were utilized for an initial analysis on the African circulation system. The specific reanalyses are (1) the National Centers for Environmental Prediction/National Center for Atmospheric Research Global Reanalysis (NCEP1) [40], (2) the NCEP/Department of Energy Global Reanalysis II (NCEP2) - the improved version of NCEP1 that included additional satellite-derived atmospheric information and newer physics schemes [41], (3) the European Centre for Medium-Range Weather Forecasts (ECMWF) 40-year Reanalysis (ERA-40) [42], (4) the ERA-Interim reanalysis, developed from ECMWF's fourdimensional variational data assimilation (4DVAR) system with T255 resolution beginning 1989 [43], and (5) the Modern Era Retrospective-analysis for Research and Applications (MERRA) developed by NASA, one that incorporates a synthesis of the current suite of satellite observations [44]. All of the reanalyses used are daily means. Because ERA-40 is only available up to 2002, the period 1989-2010 was merged with ERA-Interim by interpolating ERA-Interim's higher resolution onto ERA-40's $2.5^{\circ}$ resolution through a bilinear approach. This merged reanalysis is referred to as ERA40/I.

As will be shown, in the later part of the study, we examined the relationship of the Sahel greening with the occurrences of Atlantic tropical cyclones. Information of tropical cyclones was obtained from two sources: (1) the Atlantic Hurricane Dataset Reanalysis Project [45] for the period 1979-2009 and (2) the National Hurricane Center's Tropical Prediction Center for 2010. The analysis covers the period 1979-2010.

\section{Results}

3.1. Changes in the Sahel Climate. The change of precipitation during July-August (i.e., Sahel's rainy season) of 19792010 is illustrated in Figure 2 as latitude-time diagrams of GPCP, CMAP, UDel, and $\triangle \mathrm{OLR}\left(=235 \mathrm{Wm}^{-2}\right.$-OLR $)$, averaged between $10^{\circ} \mathrm{W}$ and $10^{\circ} \mathrm{E}$ representing the central Sahel. Here, $235 \mathrm{Wm}^{-2}$ of OLR was used as a criterion to approximate the occurrence of tropical precipitation [46]. A clear northward shift is revealed in these precipitation data and proxy, without a discernable change in the amount (as inferred from the parallel trends). This feature is indicative of the fact that the increasing Sahel rainfall is not an expansion of the seasonal rainband but rather is a result of a positional shift. On the other hand, $\triangle \mathrm{OLR}$ reveals a noticeable increase 


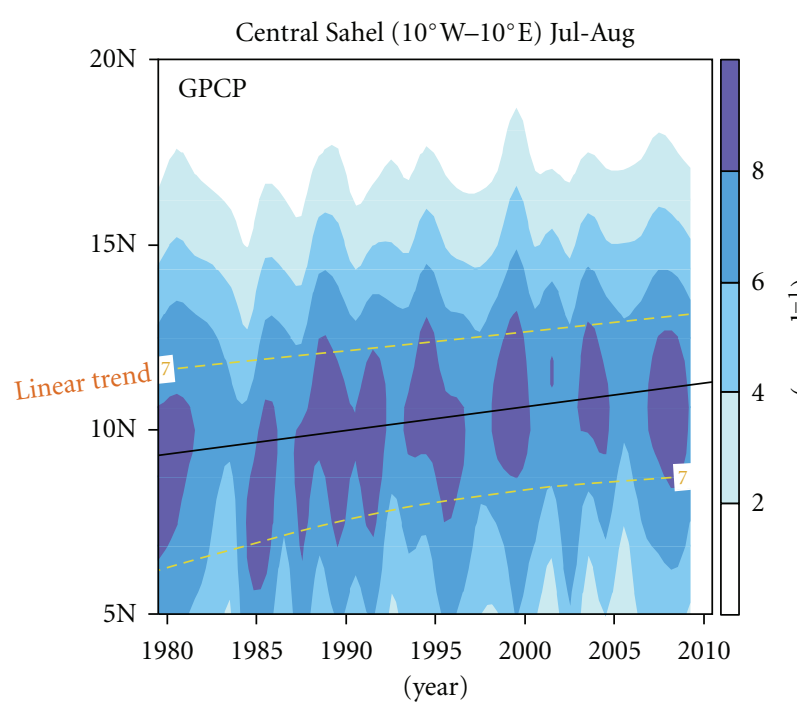

(a)

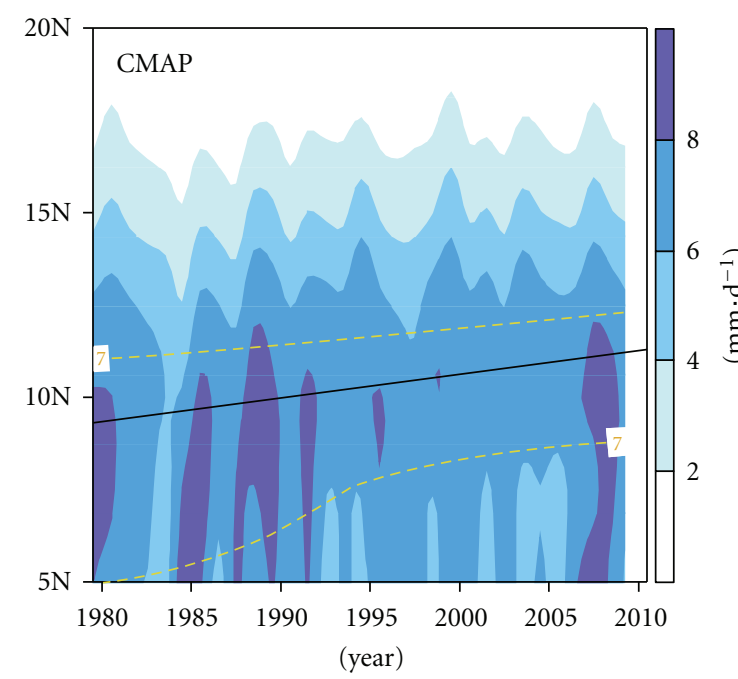

(b)

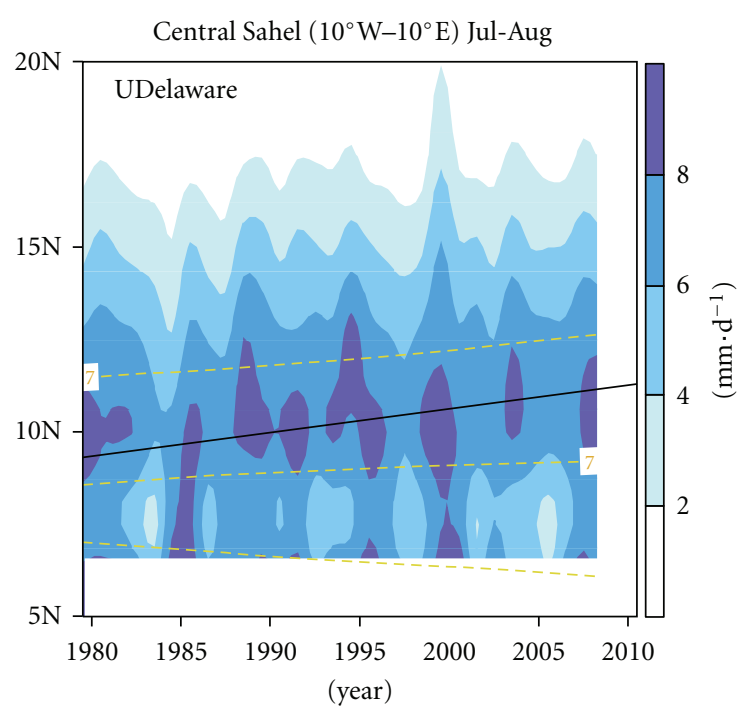

(c)

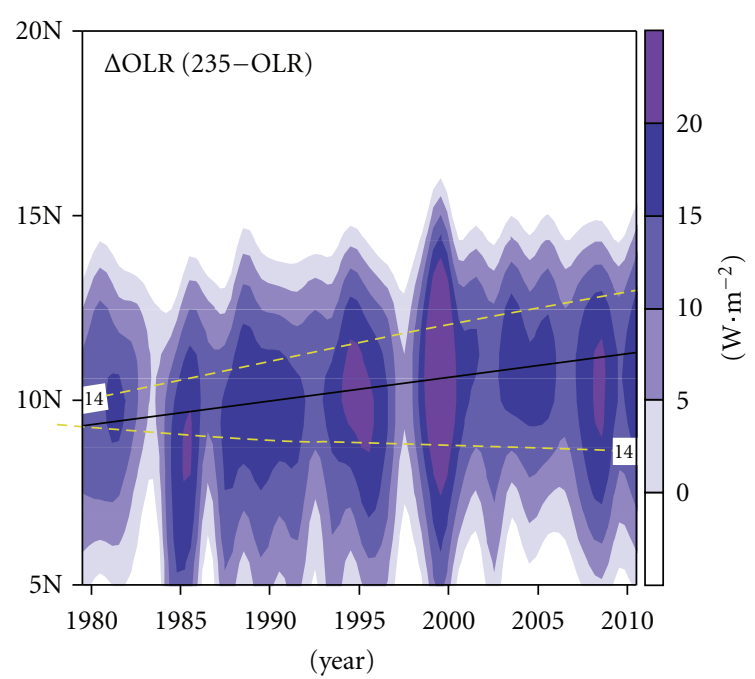

(d)

FIGURE 2: Latitude-time profiles of precipitation averaged between $10^{\circ} \mathrm{W}$ and $10^{\circ} \mathrm{E}$ for the July-August season, derived from (a) GPCP, (b) CMAP, (c) University of Delaware, and (d) $\triangle \mathrm{OLR}\left(=235 \mathrm{Wm}^{-2}-\mathrm{OLR}\right)$. Yellow dashed lines are linear trends of the designated value. The solid black lines indicate the average latitudinal position of maximum precipitation for the depiction of the Sahel rainband.

in magnitude in the precipitation condition (as noted from the diverging trends), suggestive of an intensification in the convective activity within the migrating rainbands. The latitudinal shift of the rainfall maximum-averaged from all four datasets-amounts to about $+1.1^{\circ}$ over the 32 year period and is indicated by the solid black line in Figure 2. A similar migration feature is observed over the eastern Sahel $\left(10^{\circ} \mathrm{E}-30^{\circ} \mathrm{E}\right)$, which is shown in Figure 3 with a steady northward shift of the rainband. The western Sahel (not shown) exhibits similar characteristics to that of the central Sahel. An examination of the model-generated precipitation from the four reanalyses (not shown), however, revealed a systematic bias that consisted of a southward displacement of the mean rainband (i.e., positioned at $7.5^{\circ} \mathrm{N}$ instead of $11^{\circ} \mathrm{N}$ as is the case in Figure 2), without a discernable positional shift.
Such reanalyses biases highlight a primary challenge of global climate models when it comes to producing reliable climate simulations and projections for precipitation, as was noted previously [30-32]. For this reason, we decided to use only the kinetic fields of the reanalyses.

Figure 4 shows changes in the TEJ, AEJ, and the tropical monsoon westerly in terms of zonal winds at (a) $200 \mathrm{mb}$, (b) $600 \mathrm{mb}$, and (c) $850 \mathrm{mb}$, respectively, from the four reanalyses over the central Sahel. The point to note here is that there is a substantial increase in the TEJ and a slight southward shift of the jet core, although MERRA depicts less of a positional shift but does show a much stronger jet speed compared to the other reanalyses. NCEP2 and ERA40/I depict a similar structure of the TEJ but are somewhat different from the other reanalyses. It is known that wet 


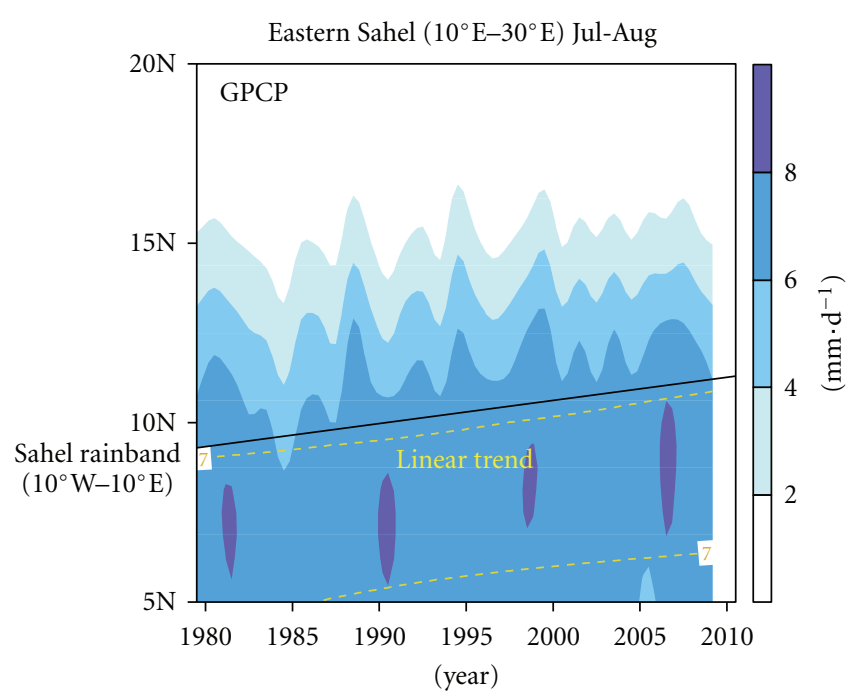

(a)

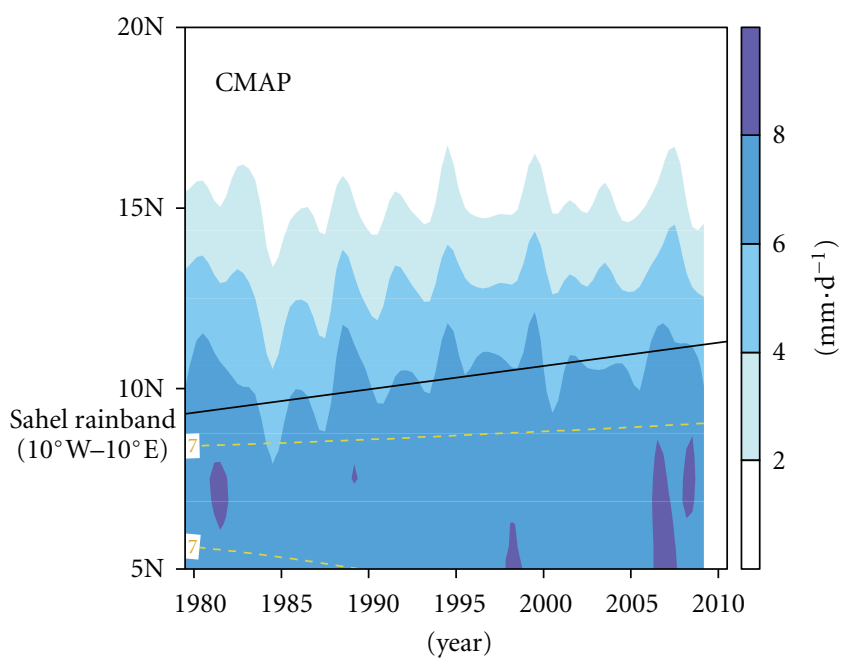

(b)

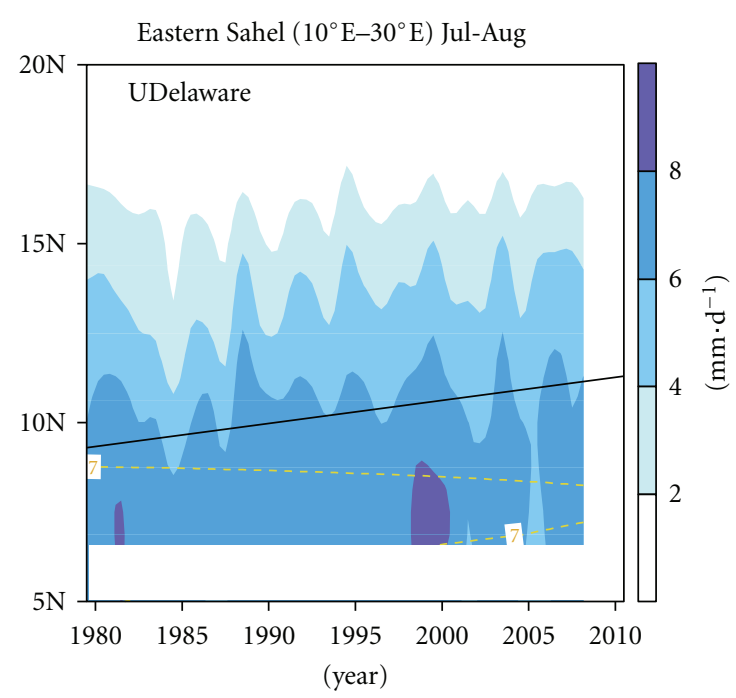

(c)

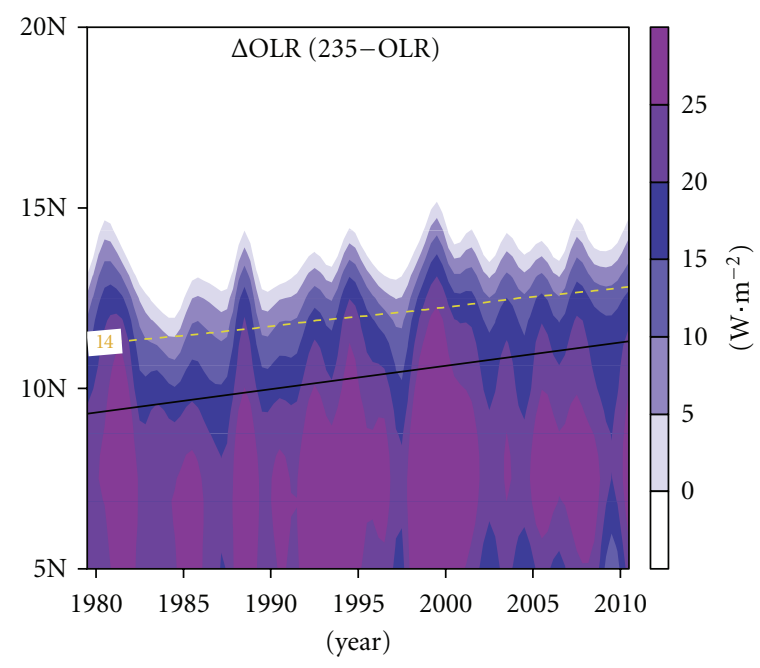

(d)

FIgURE 3: The same as Figure 2 but for the longitudinal zone of $10^{\circ} \mathrm{E}$ and $30^{\circ} \mathrm{E}$ (eastern Sahel). The black solid lines indicate the rainband as in Figure 2.

years and upward motion south of the Sahel are associated with TEJ strengthening, which is related to the El NiñoSouthern Oscillation [47-49]. However, even though the TEJ has intensified, its southward expansion does not seem to correspond to the decreased tropical rainfall (south of $10^{\circ} \mathrm{N}$, Figure 2). For the AEJ (Figure 4(b)), all the reanalyses, with the exception of MERRA, depict a northward shift of the jet consistent with the migrating rainband. Both NCEP2 and ERA40/I depict a clear intensification of the AEJ, whereas the intensification is weaker in NCEP1 and MERRA. For the tropical monsoon westerly, the reanalyses are somewhat divergent-while NCEP1 points to an increase in the westerly wind speed, ERA40/I indicates a sharp decrease. Nevertheless, all reanalyses agree upon a quasistationary behavior of the monsoon westerly. Based on Figure 4, it appears that the four reanalyses exhibit somewhat different characteristics of the African circulations. In particular, newer reanalyses do not appear to correspond with each other, such as the AEJ's trend between MERRA and ERA40/I. Therefore, in the ensuing analysis, we adopted an ensemble approach by averaging the four reanalyses with an equal weight, denoted as the ensemble reanalyses.

Recall from Figure 2 that, although the precipitation amounts have not increased significantly, $\triangle$ OLR has intensified. The root mean square (RMS) of daily OLR over the central Sahel (Figure 5(a), left) supports this observation as it reveals an enhanced fluctuation along the northern edge of the migrating rainband $\left(\sim 15^{\circ} \mathrm{N}\right)$. This likely is due to the rainband moving towards the Saharan boundary where stronger potential temperature gradients and lower static stabilities are present; this subsequently leads to greater thermal and convective instabilities (discussed later). To 

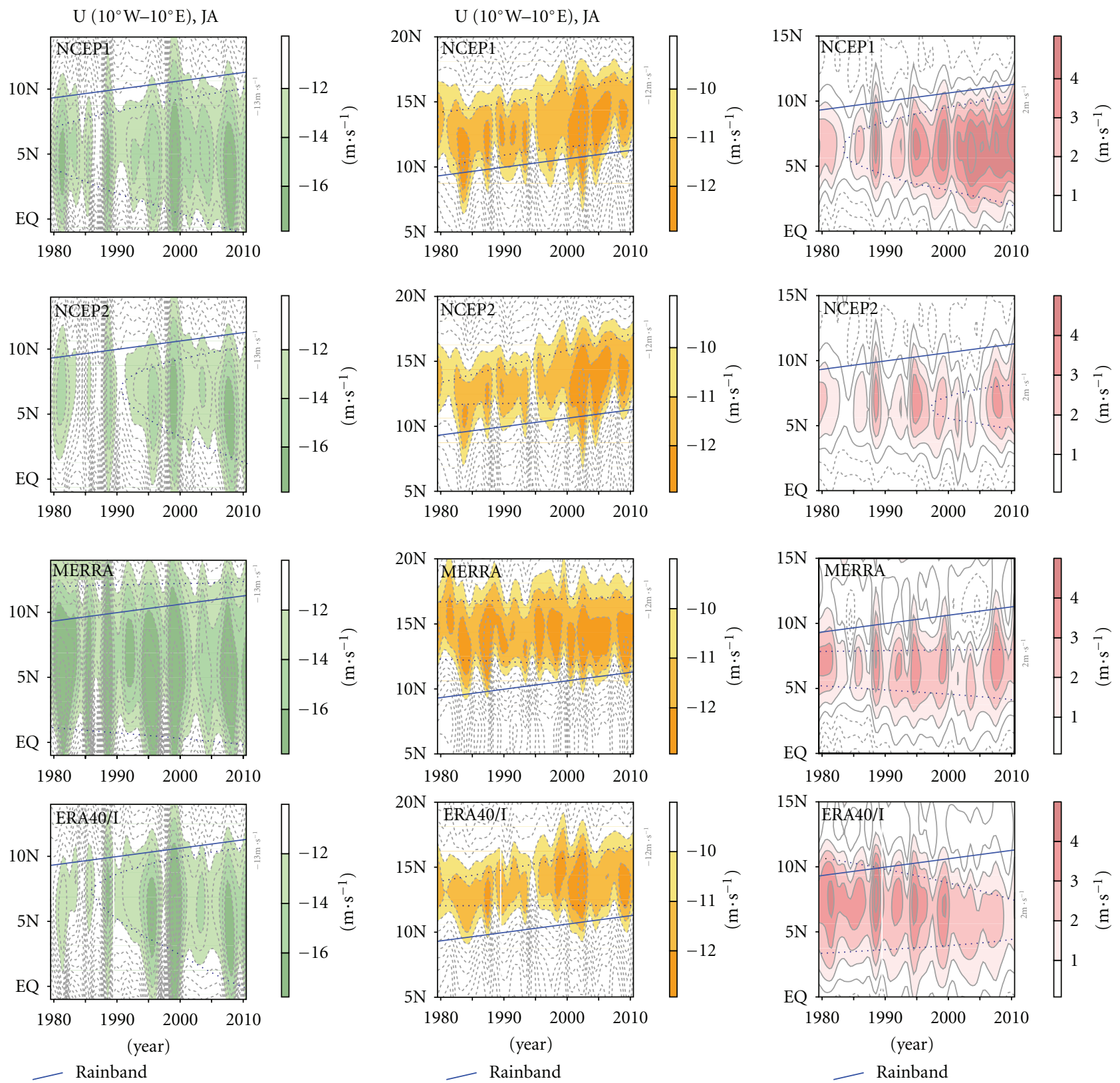

(a)

(b)

(c)

Figure 4: The same as Figure 2 but for zonal wind speeds at levels of (a) $200 \mathrm{mb}$, (b) $600 \mathrm{mb}$, and (c) $850 \mathrm{mb}$ derived from (top-down) NCEP1, NCEP2, MERRA, and ERA40/I. The solid blue lines indicate the Sahel rainband migration. The dotted lines indicate linear trends of the designated value. Note the different latitudinal scales for each level. In ERA40/I, year 1989 is masked out to highlight the transition from ERA40 to ERA-Interim.

examine the change in moist convection, we computed the frequency from which the daily OLR values at each grid point were lower than $200 \mathrm{Wm}^{-2}$, which is an empirical threshold obtained for deep convection that usually occurs over tropical oceans [50]. The result (Figure 5(b)) portrays a northward migration in the frequency of intense convection that is coupled to the migrating rainband (i.e., the blue line). However, the northernmost convective activity could be relatively shallow because the RMS(OLR) boundary extends to $17^{\circ} \mathrm{N}$ while the frequency of OLR
$<200 \mathrm{Wm}^{-2}$ only reaches $15^{\circ} \mathrm{N}$. The eastern Sahel (Figure 5, right) undergoes consistent changes in convective activity. The observed migration and intensification of moist convection are supported by enhanced moisture flows and the increased convergence in moisture fluxes towards the Sahel, as will be shown later in Section 4 (Figure 10).

It is known that, within the latitude zone of $10^{\circ}-$ $15^{\circ} \mathrm{N}$, AEWs contribute a significant portion to the seasonal precipitation [23, 51]. The association of the changing convective activity with AEWs was examined by calculating 

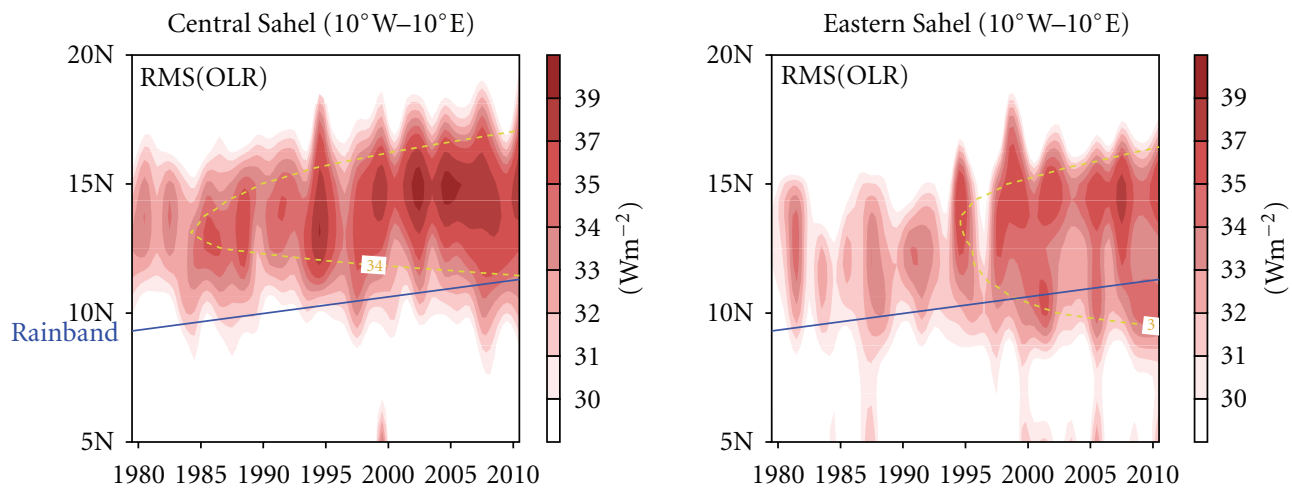

(a)
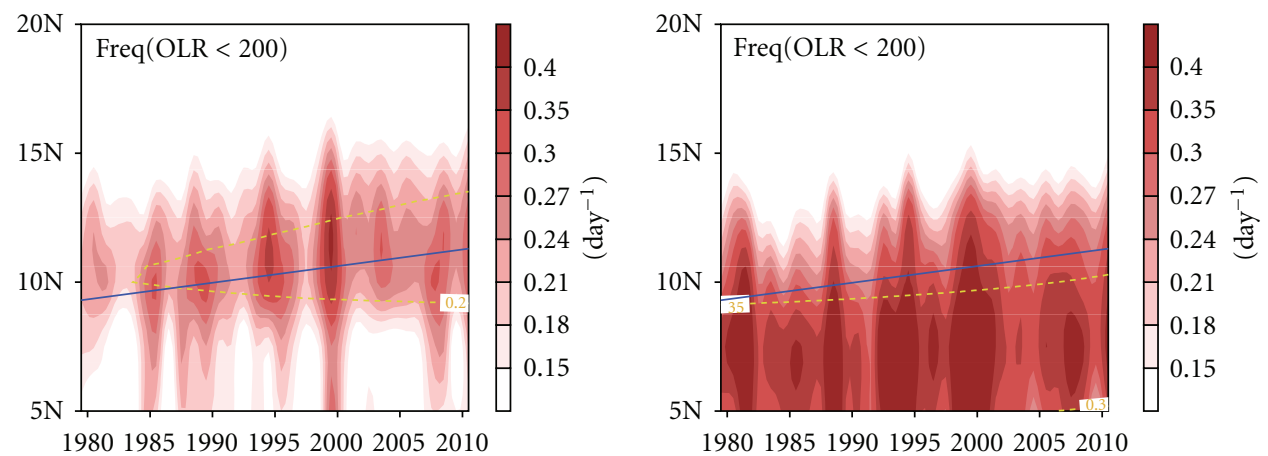

(b)
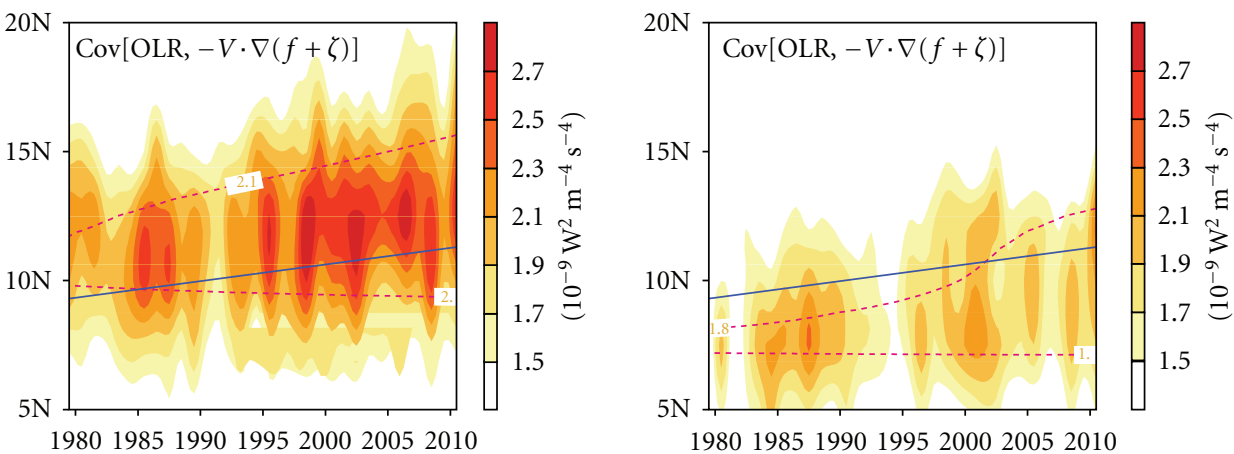

(c)
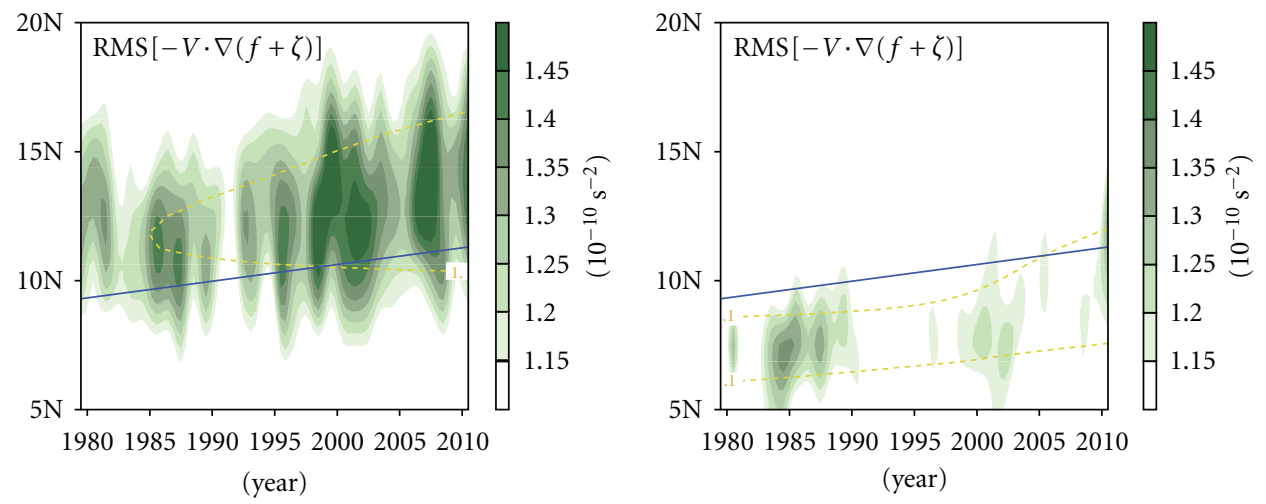

(d)

FIGURe 5: The same as Figure 4 but for (a) root mean square (RMS) of the 2-8 day bandpass filtered OLR, (b) frequency of the OLR values lower than $200 \mathrm{Wm}^{-2}$, (c) covariance of the filtered OLR with horizontal vorticity advection at $600 \mathrm{mb}$, and (d) RMS of the filtered horizontal vorticity advection at $600 \mathrm{mb}$. Dashed lines are linear trends of the designated value. The Sahel rainband is indicated by solid blue lines. 
the covariance of the $\Delta \mathrm{OLR}$ in conjunction with the vorticity advection forcing of vorticity tendency, $-\mathbf{V} \cdot \nabla(f+\zeta)$, where $\mathbf{V}$ indicates horizontal wind vectors, $f$ is the planetary vorticity, and $\zeta$ is the relative vorticity at $600 \mathrm{mb}$. Both variables were bandpass filtered with 2-8 days in order to isolate the signal of AEWs - this being based upon AEWs' distinctive timescale and following the time-filtering method used by Thorncroft and Rowell [52]. The filtered vorticity advection ( $\triangle \mathrm{OLR}$ ) accounts for $66 \%(74 \%)$ of total variance with the seasonal cycle removed.

As is shown in Figure 5(c), a substantial increase, as well as a northward position shift, is observed in the covariance of $\triangle$ OLR and vorticity advection in both central and eastern Sahel. This suggests an expansion and northward shift of the wave-convection interaction. The RMS of the filtered vorticity advection (Figure $5(\mathrm{~d})$ ) shows a similar shift with an amplifying tendency that may be interpreted as a northward displacement of the AEW track accompanied by an amplification of those waves. The wave activity in the eastern Sahel-that is, one of the breeding zones of AEWs - is generally weaker than in the central Sahel but shows a similar tendency: a northward shift and a latitudinal expansion. Using the NCEP1 data over the period 19782004, Chen and Wang [23] found a 20\% increase in the number of "moist" AEWs that occur south of the AEJ (the so-called southern track). These results indicate that the migrating convection, AEJ, and AEWs are connected with the shifting Sahel rainband and, that convection coupled to the AEJ-AEW system has become stronger over the northern part of the Sahel.

3.2. Changes in the Dynamic Structure. It is well established that the formation mechanism of AEWs, particularly the southern track, relies upon the Charney-Stern instability [53] in which the meridional gradient of potential vorticity changes sign south of the AEJ and is negative underneath the AEJ [18-20]. The Charney-Stern instability occurs in an environment of combined thermal gradient and vertical shear that promotes the release of available potential energy (from the mean circulation) towards any pressure perturbations. Therefore, we examined the change in this dynamics through the meridional gradient of potential vorticity, $d q / d y$, at $600 \mathrm{mb}$ (Figure 6(a)). Compared with the AEJ as depicted in Figure 4(b), the sign change of $d q / d y$ indeed occurs south of the jet while it exhibits a northward progression corresponding to the AEJ's migration. Noteworthy is that the intensified AEJ may also induce stronger shear instability south of the jet; this being favorable for the development of AEWs. As has been shown previously [54], midtropospheric vortex stretching is a dominant forcing source in the vorticity budget over the AEW genesis region. An examination of the seasonal mean vortex stretching at $600 \mathrm{mb}$ reveals an amplifying tendency associated with a northward migration (Figure 6(b)), with a more pronounced amplification in the eastern Sahel. These features correspond well with the intensification and positional shift of AEWs revealed from Figures 5(c) and 5(d). Since the AEW activity is positively correlated with the Sahel and the West African rainfall (i.e., on the interannual timescale) [52], these also seem to support the position shift of the Sahel rainband.

During the last 30 years, surface temperature over the Saharan desert has warmed within the range of $0.5^{\circ}-$ $1.0^{\circ} \mathrm{C}$ (not shown); a warming like this strengthens the heat low and lowers the static stability. The change in warming and static stability (from the combination of low static stability and a stronger meridional temperature gradient, [55]) likely reinforces the heat low's interaction with the northward migrating AEJ, leading to an enhancement in baroclinic instability. When coupled with the increased moisture supply (shown later in Figure 10), as well as enhanced moist convection conditions, mixed barotropic and baroclinic instabilities likely result in a stronger reversal of the midtropospheric potential vorticity gradient, as was found in earlier observations [56], thus enhancing $d q / d y$. This appears to be the case as is evident in Figure 6(a). Such processes further explain the intensified AEW-OLR activity suggested from Figure 5(c).

Apart from the Sahel, precipitation in West Africa has also increased (Figure $1, \sim 15^{\circ} \mathrm{W}$ ); this implies an intensification of the monsoon trough in that region (i.e., the monsoon trough is perceived by low-level cyclonic flows extending from West Africa into the North Atlantic). This observation is substantiated in Figure 6(c) by the increase in the vorticity source over West African and the coastal ocean $\left(30^{\circ}-15^{\circ} \mathrm{W}\right)$. The increased vorticity source also points to a stronger convergence of the monsoon trough, which contributes to the precipitation increase. These features suggest that the concurrent shifts of the Sahel rainband, the AEJ, and associated AEWs are likely linked to the intensifications of the West African monsoon [57, 58], where they connect to the AMO-induced ITCZ anomalies. Such a connection has an implication on changes in the Atlantic tropical cyclone frequency, which will be discussed in Section 4 .

3.3. Changes in SSTs. It is known that rainfall in West Africa and the Sahel is modulated by SST variations around the globe. For instance, interannual variations of the West African monsoon closely respond to SSTs in the Gulf of Guinea, while interdecadal variations of the Sahel rainfall rise to combined effects of the AMO, the Interdecadal Pacific Oscillation, and the Indian Decadal Variability [11, 59]. Here, we examined the meridional evolution of SSTs in the Atlantic $\left(40^{\circ}-20^{\circ} \mathrm{W}\right)$ and the Gulf of Guinea $\left(10^{\circ} \mathrm{W}-10^{\circ} \mathrm{E}\right)$, shown, respectively, in Figures 7 (a) and 7(b). The warm SST zone in the tropical Atlantic has expanded, with its northern boundary (e.g., the $27^{\circ} \mathrm{C}$ isotherm) progressing northward at about the same rate as the Sahel rainband. The tropical South Atlantic has also warmed. In the Gulf of Guinea, a discernable, but less pronounced warming is observed. Warming in the Gulf of Guinea is known to decrease the meridional temperature gradient, which subsequently reduces the West African monsoon, at least on the interannual timescale. This appears to be the case for surface thermal gradients derived from the CRU temperatures in the central Sahel (Figure 7(c)). There, the northward shift in positive meridional temperature gradients is in agreement with the migrating rainband. 

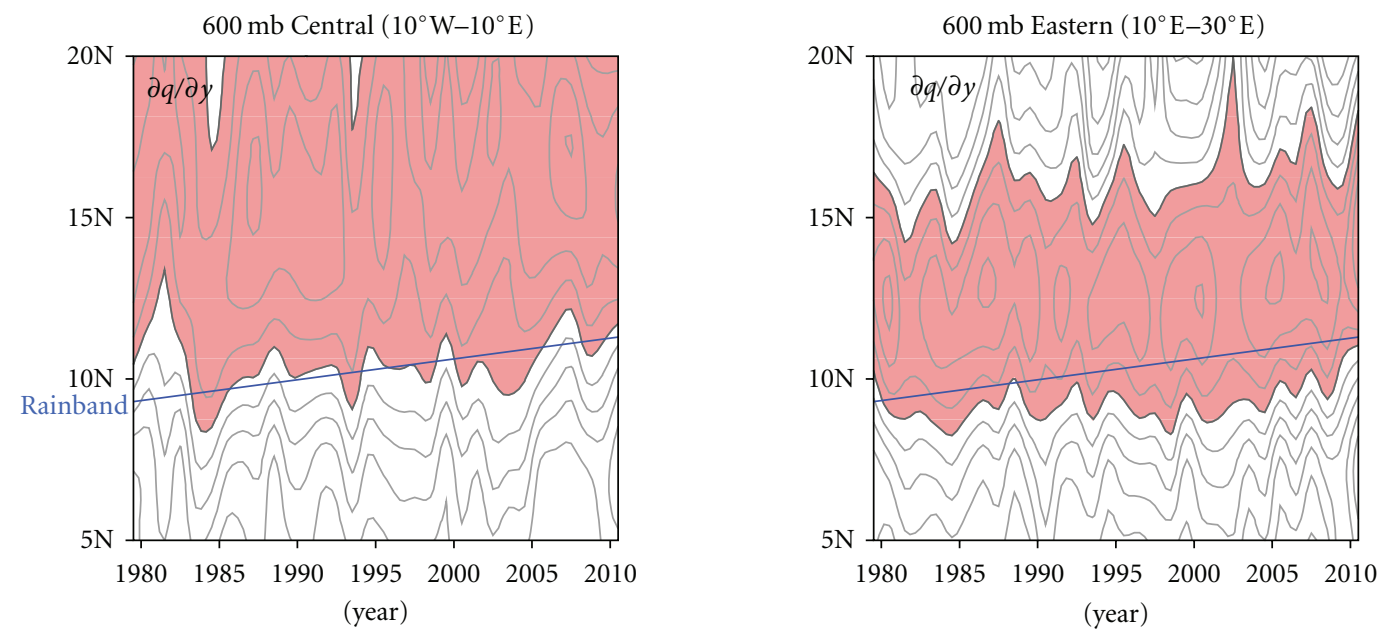

(a)
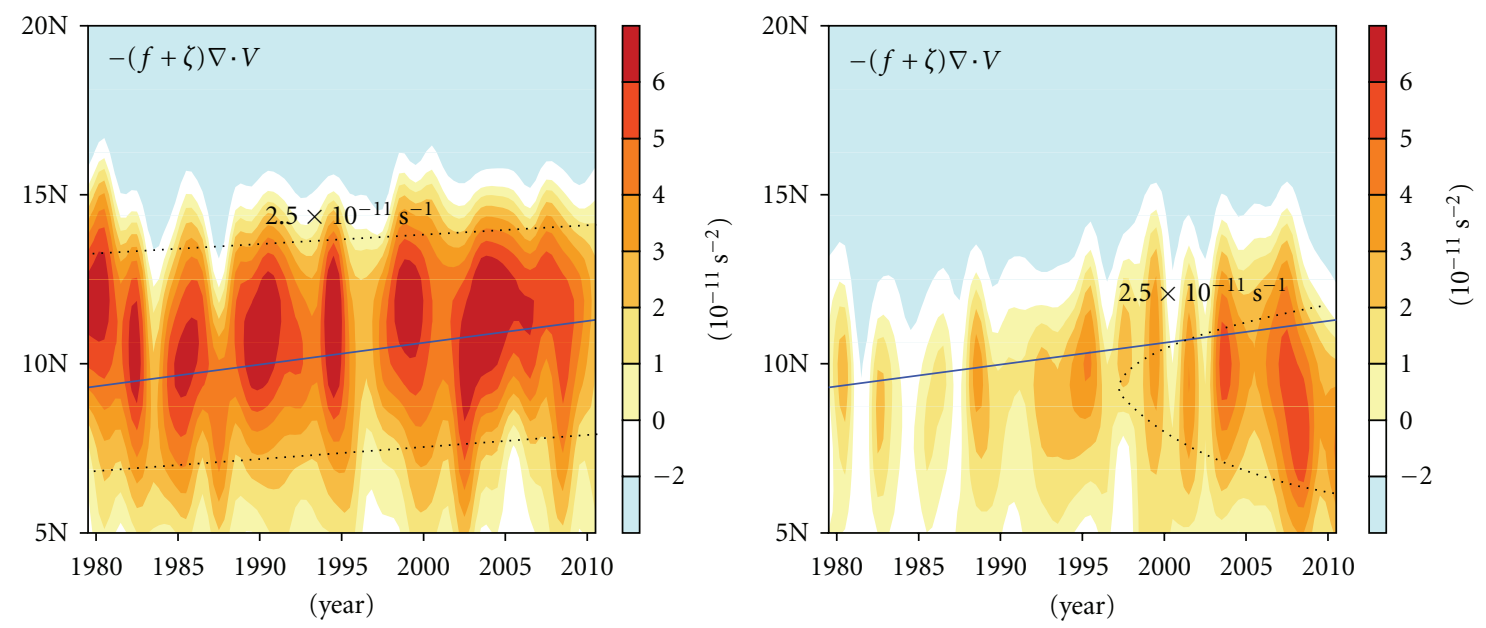

(b)

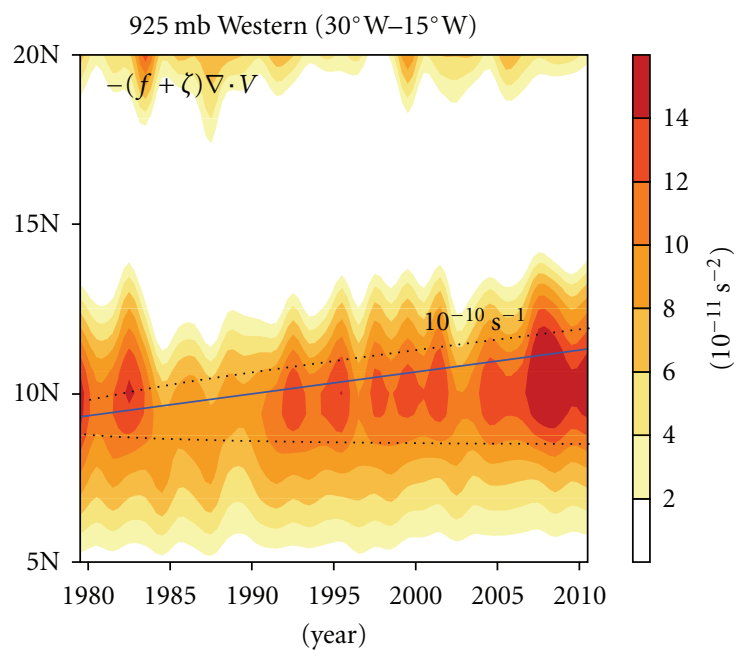

(c)

Figure 6: The same as Figure 5 but for (a) meridional gradient of Ertel potential vorticity at $600 \mathrm{mb}$, (b) vorticity source due to vortex stretching at $600 \mathrm{mb}$, and (c) vorticity source at $925 \mathrm{mb}$ averaged between $30^{\circ}-15^{\circ} \mathrm{W}$. Black dotted lines are linear trends of the designated value. The eastern Sahel conditions are shown in the right with respect to (a) and (b). 


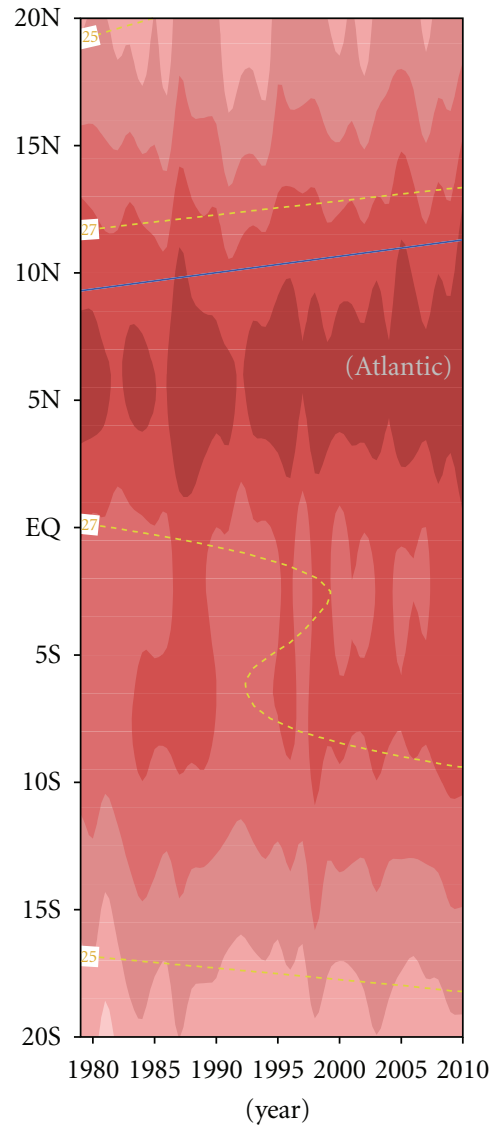

(a)

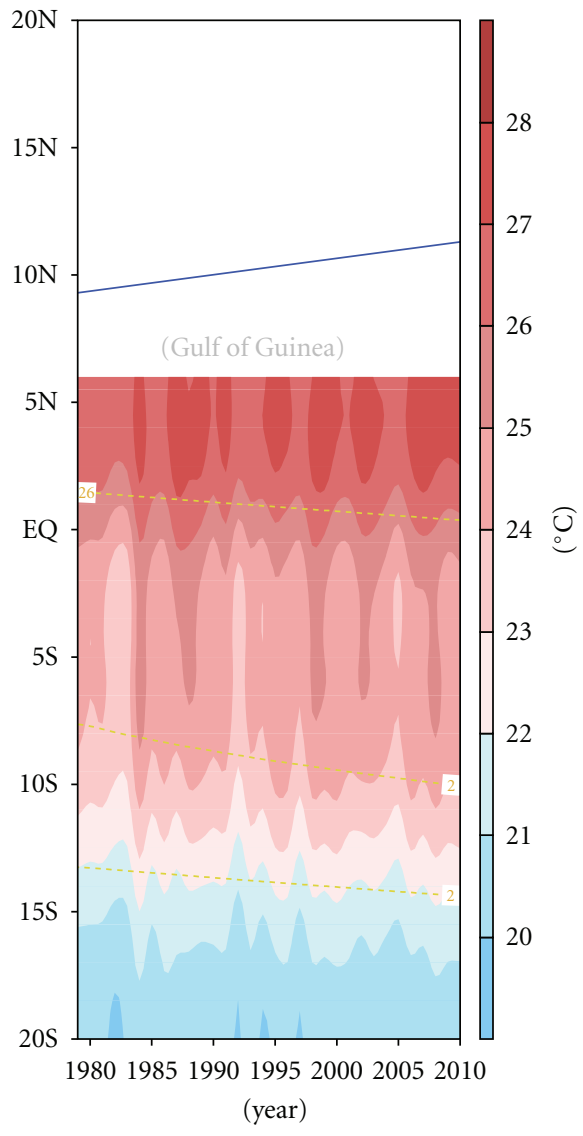

(b)

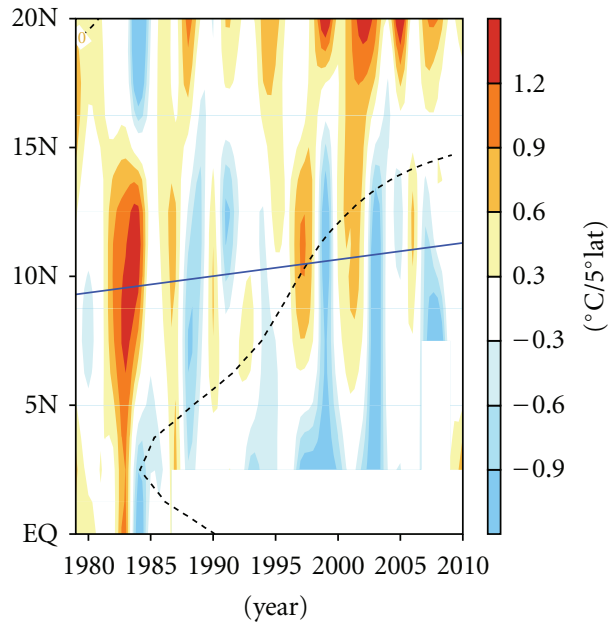

(c)

FIGURE 7: Evolution of SSTs over (a) Atlantic $40^{\circ} \mathrm{W}-20^{\circ} \mathrm{W}$ and (b) Gulf of Guinea $10^{\circ} \mathrm{W}-10^{\circ}$ E superimposed with the linear trends (yellow dashed lines) and the Sahel rainband (thick blue line). (c) Evolution of the meridional gradient of CRU surface temperature anomalies over the central Sahel $10^{\circ} \mathrm{W}-10^{\circ} \mathrm{E}$.

\section{Link with Atlantic Tropical Cyclones}

During the past 30 years, both the frequency and the intensity of Atlantic tropical cyclones have increased significantly. The increase is, at least in part, attributed to rising tropical SSTs [33]. Recently, a growing number of studies have suggested that tropical cyclone activity and Sahel rainfall anomalies are linked to the uptrend phase of the AMO (as reviewed by Latif et al. [10]), but such a linkage has not yet been substantiated. Landsea [26] has estimated that about $60 \%$ of tropical storms and moderate tropical cyclones in the Atlantic basin and over $80 \%$ of intense tropical cyclones (i.e., Category 3 and above) originate from AEWs. Later studies $[25,28,29]$ found that southern-track AEWs contribute the most to tropical cyclogenesis, because their nature of moist convection facilitates the conversion of cold-core waves into warm-core tropical cyclones [60]. Here, we explored their synoptic linkage.

The Atlantic tropical cyclogeneses and those that originate from AEWs was examined by performing a backtracking method of AEWs as was used in Chen et al. [28]. The back-tracking procedure begins with the genesis location of a tropical cyclone, then tracks any preexisting perturbation associated with the tropical cyclogenesis back to its origin of perturbation by using daily-mean wind and vorticity fields at $925 \mathrm{mb}$ and $600 \mathrm{mb}$ in conjunction with daily OLR. Here, if the perturbation originated over the African continent, then its related tropical cyclogenesis is regarded as being of AEW origin. The tracking was performed manually, and only those tropical cyclones during the period 20052010 were tracked, while cases prior to 2005 were adopted from Chen et al. [28]. Illustrated in Figure 8 are tropical cyclogeneses with an AEW origin, the initial locations of those AEWs, and the trajectory between the two. As was previously observed [28], southern-track AEWs tend to form tropical cyclones further to the east and closer to West Africa than northern-track AEWs, likely due to stronger latent heat release in the West African monsoon region [25].

Figure 9(a) shows the number of tropical cyclones initiated in the July-September season and their linear trend. Year 2010 was not included in the trend analysis because the track records at the time were provisional. Of the $86 \%$ increase in the number of tropical cyclones since 1979, 62\% originated from AEWs (Figure 9(b)) while 50\% are linked to southern-track AEWs (Figure 9(c)). The connection between AEWs and intense tropical cyclones is more pronounced: 


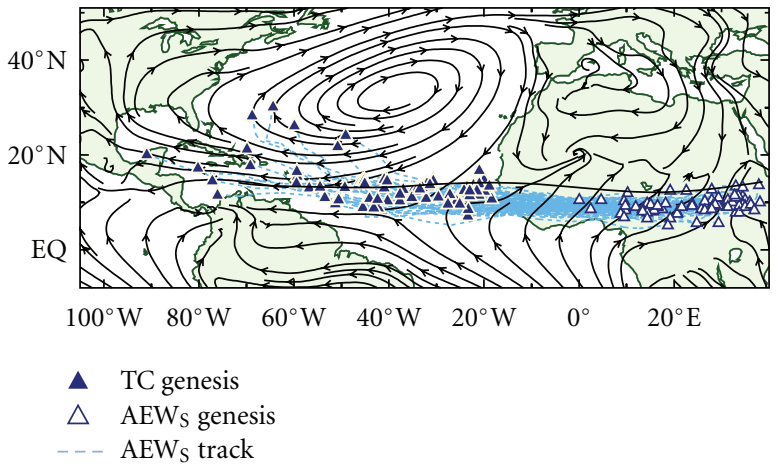

(a)

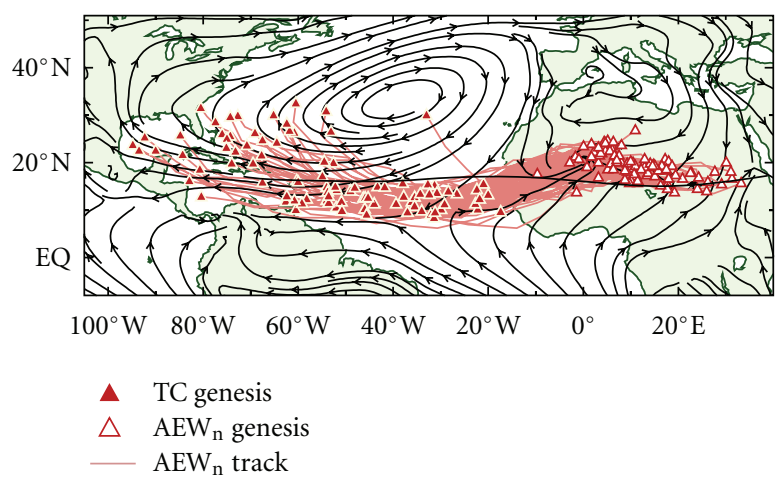

(b)

FIGURE 8: (Modified from Chen et al. [28]) July-September climatological streamlines at 925 mb overlaid with tropical cyclogeneses of AEW origin and the trajectory and genesis of AEWs for $(a)$ the southern track $\left(A_{E W}\right)$ and (b) the northern track $\left(A_{E W}\right)$. Symbols are explained in the right. The AEJ core is indicated by the black solid line. Data period: 1979-2006.

given a dramatic $148 \%$ increase in the number of intense tropical cyclones, $88 \%$ are of AEW origin (Figure $9(\mathrm{e})$ ), while $84 \%$ (out of the $88 \%$ ) originated from the southern-track of AEWs (Figure 9(f)). It has been found that the large-scale atmospheric conditions leading to the increase in tropical cyclone frequency and power involve potential intensity (potential intensity involves net surface radiation, thermodynamic efficiency, and surface wind speed.), low-level vorticity, and vertical wind shear [34], whose variations turn to the favorable side for tropical cyclogenesis during the recent AMO uptrend [8, 10]. Nonetheless, the ensuing change in synoptic process has not been explored. Therefore, the results presented in Figure 9 are a further substantiation of the synoptic condition and associated dynamic linkage that exist to "fuel" the observation of increasing rainfall in the Sahel and the Atlantic tropical cyclones (especially the intense ones).

As an attempt to reconcile the large-scale and synoptic perspectives for the observed changes in tropical cyclones and AEWs, we examined the large-scale moisture flows by computing the potential function and streamfunction of the atmospheric column water vapor flux, $\mathbf{Q}$, denoted, respectively, by VPQ and STQ [61]:

$$
\begin{gathered}
\mathrm{VPQ}=\nabla^{-2}(\nabla \cdot \mathbf{Q}), \\
\mathrm{STQ}=\nabla^{-2}(\vec{k} \cdot \nabla \times \mathbf{Q}) .
\end{gathered}
$$

The horizontal distribution of the linear trends of VPQ (Figure 10(a)) depicts a convergence center off the coast of West Africa, accompanied by an elongated region of convergent water vapor flux over the Sahel. These features indicate an increase in moisture pooling, hence supporting the precipitation increase (cf., Figure 1). Meanwhile, a robust cyclonic circulation of STQ is formed over the tropical Atlantic, centered to the west of the VPQ convergence maximum (Figure 10(b)) and corresponding to the SST warming (Figure 7(a)). Since STQ resembles the lowertropospheric circulation, this cyclonic STQ anomaly also illustrates the deepening of the monsoon trough (which connects to the ITCZ in the west). Associated with this cyclonic STQ anomaly, the enhanced monsoon trough $\left(\sim 15^{\circ} \mathrm{N}\right)$ affects West Africa and extends inland up to $20^{\circ} \mathrm{E}$, thereby strengthening the moisture supply into the Sahel. This deepening of the West African monsoon trough has also been noted in Nicolson [62].

Next, we superimposed the location of tropical cyclogeneses during the two periods of 1979-1995 (blue dots) and 1996-2010 (red dots) with Figure 10. It appears that most of the increase in tropical cyclogenesis is distributed east of $50^{\circ} \mathrm{W}$. Chen et al. [28] have shown that the majority of intense tropical cyclones with AEW origin were initiated east of $45^{\circ} \mathrm{W}$, often within the influence of the West African monsoon trough that provides low-level cyclonic vorticity, moisture flux convergence, and latent heat. These conditions appear to have intensified altogether over the last 30 years. It is possible that the enhancement of these circulation features facilitates the moist convection process that can effectively transform AEWs into tropical cyclones. There is one remaining question, though, which is to what extent the conversion rate of AEWs becoming tropical cyclones has changed? It was noted that such a conversion rate has not changed significantly [27], an observation that reflects the concurrent increases in the AEW and tropical cyclone activities [29]. However, a satisfactory answer to this question requires a systematic investigation of the conversion rate; this means persistent manual tracking for AEWs using the four or more reanalyses-a labor-intense task that is being undertaken.

\section{Concluding Remarks}

Increased Sahel rainfall over the 1979-2010 period and associated synoptic conditions were investigated. Latitudetime cross-sections of precipitation and OLR indicate that the precipitation increase in the Sahel results from the northward migration of the seasonal rainband. Convective activity associated with the migrating rainband also intensified, mostly along the northern boundary of the rainband and south of the AEJ. Analyses of kinematic fields further indicate 


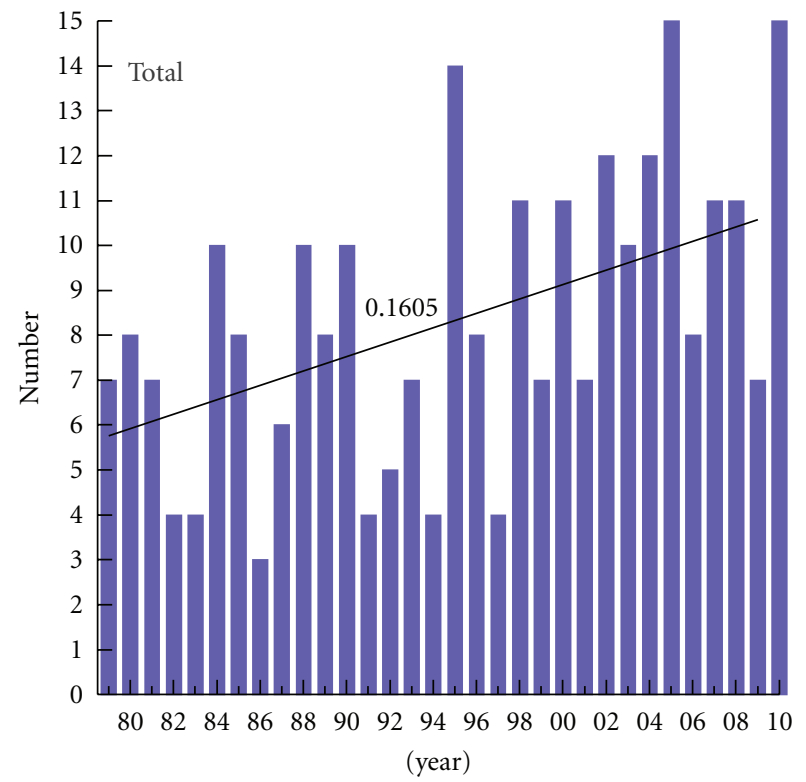

(a) TC

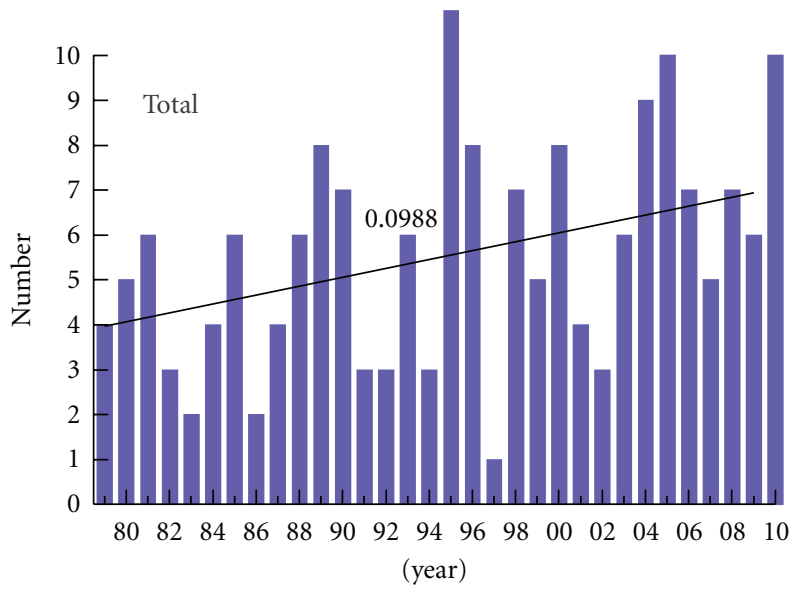

(b) AEW $\rightarrow$ TC

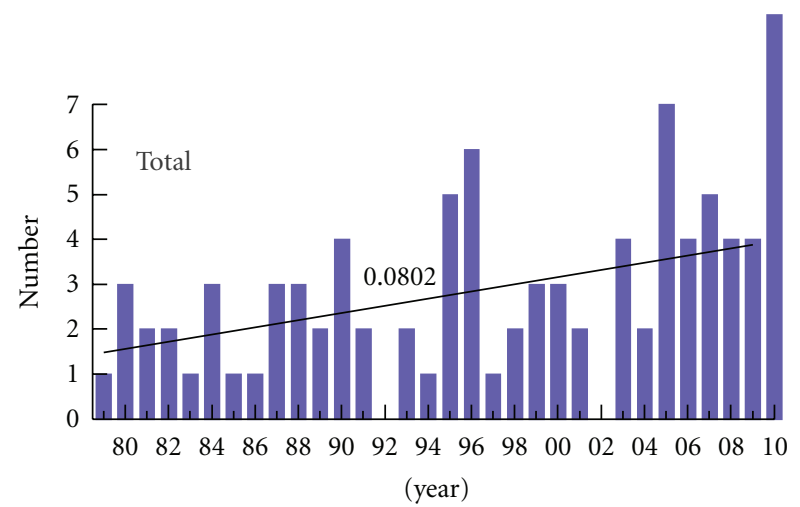

(c) $\mathrm{AEW}_{\mathrm{s}} \rightarrow \mathrm{TC}$

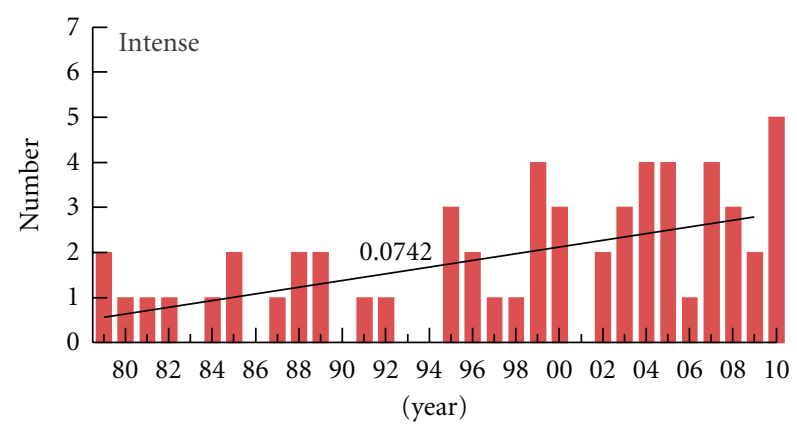

(d) TC

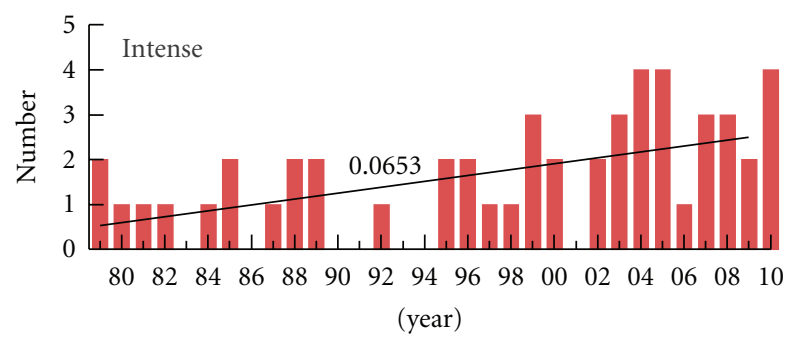

(e) AEW $\rightarrow$ TC

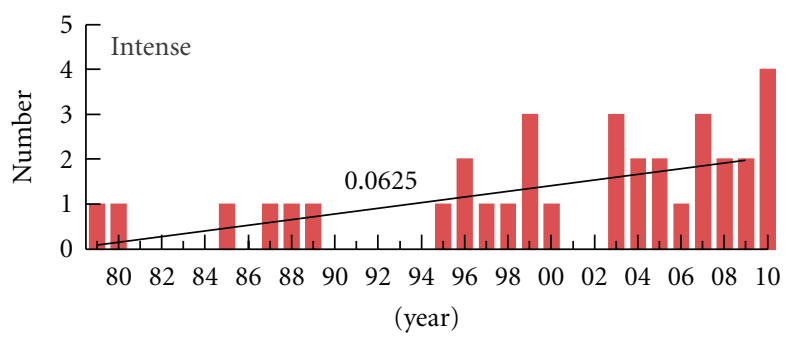

(f) $\mathrm{AEW}_{\mathrm{s}} \rightarrow \mathrm{TC}$

Figure 9: Number of Atlantic tropical cyclones (TCs) during July-September, for (a) total TCs, (b) AEW-induced TCs, and (c) southerntrack AEW-induced TCs. (d)-(f) same as (a)-(c) but for intense TCs of Category 3 and above. The linear trends and slopes are given. All trends are significant at the $95 \%$ confidence interval per $t$-test. 


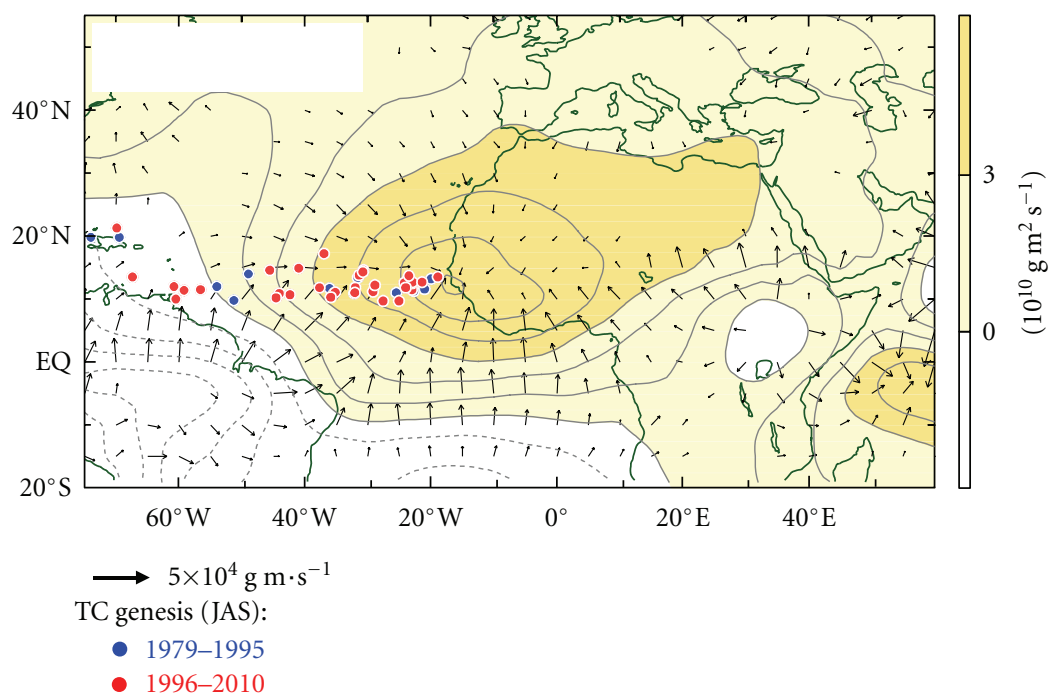

(a)

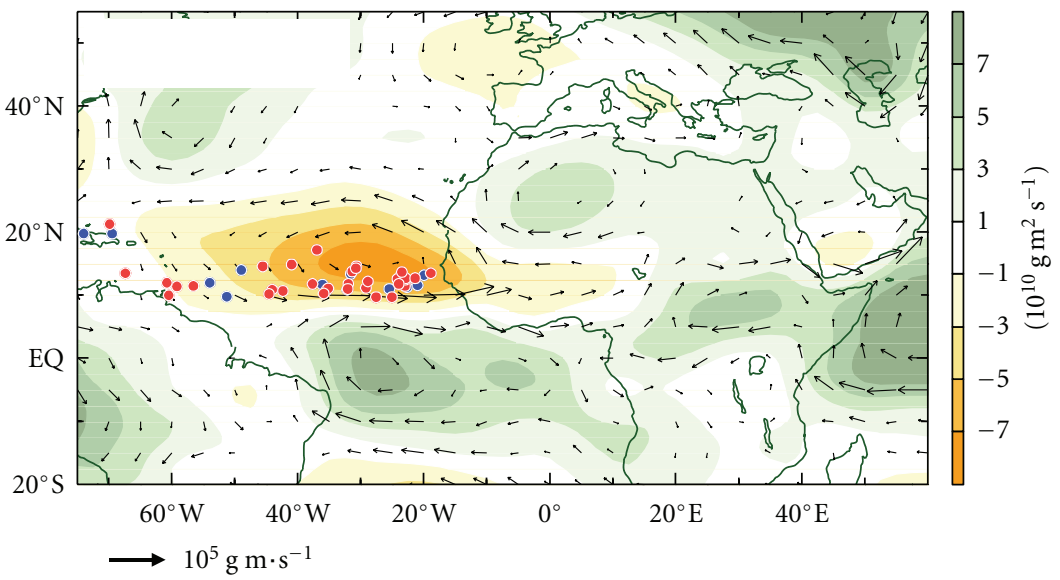

TC genesis (JAS):

- 1979-1995

- 1996-2010

(b)

FIGURE 10: Horizontal maps of linear trends of (a) the potential function (VPQ; contours + shadings) and (b) the stream function (STQ; shadings) of the column-integrated water vapor flux $\mathbf{Q}=\int_{p_{S}}^{200 \mathrm{hPa}} \overrightarrow{\mathrm{V}} q \cdot d p$, superimposed with the divergent and rotational components of the water vapor flux (vectors). Tropical cyclogeneses during the 1979-1995 and 1996-2010 periods are overlaid as blue dots and red dots, respectively.

a positional shift and intensification of the AEJ, consistent with the northward migration of the Sahel rainband. These features are accompanied by stationary tropical monsoon westerlies, an expanding TEJ, and an increase in moisture flux convergence. Concurrent tropical SSTs in the Atlantic also contribute to the enhancement of low-level cyclonic flows that extend into the Sahel.

Furthermore, the poleward shift and amplification of AEW activity associated with the AEJ changes play a crucial role in the change of tropical cyclogenesis over the North Atlantic. Through a manual back-tracking method that connects tropical cyclones to their AEW origin, it was found that $88 \%$ of the dramatic $148 \%$ increase in intense tropical cyclones are linked to AEWs. These results provide a synoptic linkage between the documented increase in tropical cyclone threat and the increasing Sahel rainfall over the past 30 years. In view of the severe spreads in GCM projections of the Sahel climate, simulation quality in terms of the AEJ-AEW system may serve as an additional criterion for the assessment of projection uncertainties. Moreover, projected AEW activities may also provide an indication for future tropical cyclone threat.

\section{Acknowledgment}

This study was supported in part by the Utah Agricultural Experiment Station, Utah State University and approved as Journal Paper no. 8293 and by the United States Agency for 
International Development through Grant no. EEM-A-0010-00001.

\section{References}

[1] L. Olsson, L. Eklundh, and J. Ardö, "A recent greening of the Sahel-trends, patterns and potential causes," Journal of Arid Environments, vol. 63, no. 3, pp. 556-566, 2005.

[2] S. M. Herrmann, A. Anyamba, and C. J. Tucker, "Recent trends in vegetation dynamics in the African Sahel and their relationship to climate," Global Environmental Change, vol. 15, no. 4, pp. 394-404, 2005.

[3] A. H. Fink, J. M. Schrage, and S. Kotthaus, "On the potential causes of the nonstationary correlations between West African precipitation and atlantic hurricane activity," Journal of Climate, vol. 23, no. 20, pp. 5437-5456, 2010.

[4] A. Dai, P. J. Lamb, K. E. Trenberth, M. Hulme, P. D. Jones, and P. Xie, "The recent Sahel drought is real," International Journal of Climatology, vol. 24, no. 11, pp. 1323-1331, 2004.

[5] S. E. Nicholson and X. Yin, "Rainfall conditions in equatorial East Africa during the nineteenth century as inferred from the record of Lake Victoria," Climatic Change, vol. 48, no. 2-3, pp. 387-398, 2001.

[6] J. Lu and T. L. Delworth, "Oceanic forcing of the late 20th century Sahel drought," Geophysical Research Letters, vol. 32, no. 22, Article ID L22706, pp. 1-5, 2005.

[7] S. M. Hagos and K. H. Cook, "Ocean warming and latetwentieth-century Sahel drought and recovery," Journal of Climate, vol. 21, no. 15, pp. 3797-3814, 2008.

[8] M. Hoerling, J. Hurrell, J. Eischeid, and A. Phillips, "Detection and attribution of twentieth-century northern and southern African rainfall change," Journal of Climate, vol. 19, no. 16, pp. 3989-4008, 2006.

[9] K. H. Cook, "Climate science: the mysteries of Sahel droughts," Nature Geoscience, vol. 1, no. 10, pp. 647-648, 2008.

[10] M. Latif, "Dynamics of decadal climate variability and implications for its prediction," in Proceedings of the Sustained Ocean Observations and Information for Society (OceanObs '09), J. Hall, D. E. Harrison, and D. Stammer, Eds., 2010.

[11] A. Giannini, R. Saravanan, and P. Chang, "Oceanic forcing of Sahel rainfall on interannual to interdecadal time scales," Science, vol. 302, no. 5647, pp. 1027-1030, 2003.

[12] D. S. Schimel, J. I. House, K. A. Hibbard et al., "Recent patterns and mechanisms of carbon exchange by terrestrial ecosystems," Nature, vol. 414, no. 6860, pp. 169-172, 2001.

[13] C. Caminade and L. Terray, "Twentieth century Sahel rainfall variability as simulated by the ARPEGE AGCM, and future changes," Climate Dynamics, vol. 35, no. 1, pp. 75-94, 2010.

[14] J. Bader and M. Latif, "North Atlantic oscillation response to anomalous Indian ocean SST in a coupled GCM," Journal of Climate, vol. 18, no. 24, pp. 5382-5389, 2005.

[15] J. R. Knight, R. J. Allan, C. K. Folland, M. Vellinga, and M. E. Mann, "A signature of persistent natural thermohaline circulation cycles in observed climate," Geophysical Research Letters, vol. 32, no. 20, Article ID L20708, pp. 1-4, 2005.

[16] B. Rodríguez-Fonseca, S. Janicot, E. Mohino et al., "Interannual and decadal SST-forced responses of the West African monsoon," Atmospheric Science Letters, vol. 12, no. 1, pp. 6774, 2011.

[17] J. R. Knight, C. K. Folland, and A. A. Scaife, "Climate impacts of the Atlantic multidecadal oscillation," Geophysical Research Letters, vol. 33, no. 17, Article ID L17706, 2006.
[18] R. W. Burpee, "The origin and structure of easterly waves in the lower troposphere of North Africa," Journal of the Atmospheric Sciences, vol. 29, no. 1, pp. 77-90, 1972.

[19] C. D. Thorncroft and B. J. Hoskins, "An idealized study of African easterly waves. I: a linear view," Quarterly JournalRoyal Meteorological Society, vol. 120, no. 518, pp. 953-982, 1994.

[20] C. D. Thorncroft and B. J. Hoskins, "An idealized study of African easterly waves. II: a nonlinear view," Quartlery Journal—Royal Meteorological Society, vol. 120, no. 518, pp. 983-1015, 1994.

[21] V. Mathon, H. Laurent, and T. Lebel, "Mesoscale convective system rainfall in the Sahel," Journal of Applied Meteorology, vol. 41, no. 11, pp. 1081-1092, 2002.

[22] R. J. Reed, E. Klinker, and A. Hollingsworth, “The structure and characteristics of African easterly wave disturbances as determined from the ECMWF operational analysis/forecast system," Meteorology and Atmospheric Physics, vol. 38, no. 12, pp. 22-33, 1988.

[23] T. C. Chen and S.-Y. Wang, "Interannual variation of the Sahel rainfall," in Proceedings of the European Geosciences Union Symposium of Precipitation Science, vol. 9, Vienna, Austria, 2007.

[24] W. M. Gray and C. W. Landsea, "African rainfall as a precursor of hurricane-related destruction on the US east coast," Bulletin-American Meteorological Society, vol. 73, no. 9, pp. 1352-1364, 1992.

[25] C. Thorncroft and K. Hodges, "African easterly wave variability and its relationship to Atlantic tropical cyclone activity," Journal of Climate, vol. 14, no. 6, pp. 1166-1179, 2001.

[26] C. W. Landsea, "A climatology of intense (or major) Atlantic hurricanes," Monthly Weather Review, vol. 121, no. 6, pp. 1703-1713, 1993.

[27] C. W. Landsea and W. M. Gray, "The strong association between western sahelian monsoon rainfall and intense atlantic hurricanes," Journal of Climate, vol. 5, no. 5, pp. 435453, 1992.

[28] T. C. Chen, S. Y. Wang, and A. J. Clark, "North Atlantic hurricanes contributed by African esterly waves north and south of the African easterly jet," Journal of Climate, vol. 21, no. 24, pp. 6767-6776, 2008.

[29] S. B. Hopsch, C. D. Thorncroft, K. Hodges, and A. Aiyyer, "West African storm tracks and their relationship to Atlantic tropical cyclones," Journal of Climate, vol. 20, no. 11, pp. $2468-$ 2483, 2007.

[30] I. M. Held, T. L. Delworth, J. Lu, K. L. Findell, and T. R. Knutson, "Simulation of Sahel drought in the 20th and 21st centuries," Proceedings of the National Academy of Sciences of the United States of America, vol. 102, no. 50, pp. 17891-17896, 2005.

[31] K. H. Cook and E. K. Vizy, "Coupled model simulations of the West African monsoon system: twentieth- and twenty-firstcentury simulations," Journal of Climate, vol. 19, no. 15, pp. 3681-3703, 2006.

[32] J. H. Christensen, T. R. Carter, M. Rummukainen, and G. Amanatidis, "Evaluating the performance and utility of regional climate models: the PRUDENCE project," Climatic Change, vol. 81, no. 1, pp. 1-6, 2007.

[33] K. Emanuel, "Increasing destructiveness of tropical cyclones over the past 30 years," Nature, vol. 436, no. 7051, pp. 686$688,2005$.

[34] K. Emanuel, "Environmental factors affecting tropical cyclone power dissipation," Journal of Climate, vol. 20, no. 22, pp. 5497-5509, 2007. 
[35] P. Xie and P. A. Arkin, "Global precipitation: a 17-year monthly analysis based on gauge observations, satellite estimates, and numerical model outputs," Bulletin of the American Meteorological Society, vol. 78, no. 11, pp. 2539-2558, 1997.

[36] R. F. Adler, G. J. Huffman, A. Chang et al., "The version2 global precipitation climatology project (GPCP) monthly precipitation analysis (1979-present)," Journal of Hydrometeorology, vol. 4, no. 6, pp. 1147-1167, 2003.

[37] D. R. Legates and C. J. Willmott, "Mean seasonal and spatial variability in gauge-corrected, global precipitation," International Journal of Climatology, vol. 10, no. 2, pp. 111127,1990

[38] T. M. Smith and R. W. Reynolds, "Extended reconstruction of global sea surface temperatures based on COADS data (18541997)," Journal of Climate, vol. 16, no. 10, pp. 1495-1510, 2003.

[39] P. Brohan, J. J. Kennedy, I. Harris, S. F. B. Tett, and P. D. Jones, "Uncertainty estimates in regional and global observed temperature changes: a new data set from 1850," Journal of Geophysical Research D, vol. 111, no. 12, Article ID D12106, 2006.

[40] E. Kalnay, M. Kanamitsu, R. Kistler et al., "The NCEP/NCAR 40-year reanalysis project," Bulletin of the American Meteorological Society, vol. 77, no. 3, pp. 437-471, 1996.

[41] M. Kanamitsu, W. Ebisuzaki, J. Woollen et al., "NCEPDOE AMIP-II reanalysis (R-2)," Bulletin of the American Meteorological Society, vol. 83, no. 11, pp. 1631-1559, 2002.

[42] S. M. Uppala, P. W. Kållberg, A. J. Simmons et al., "The ERA40 re-analysis," Quarterly Journal of the Royal Meteorological Society, vol. 131, no. 612, pp. 2961-3012, 2005.

[43] A. S. Simmons, D. D. Uppala, and S. Kobayashi, "ERA-interim: new ECMWF reanalysis products from 1989 onwards," CMWF Newsl, vol. 110, pp. 29-35, 2007.

[44] M. M. Rienecker, M. J. Suarez, R. Gelaro et al., "MERRA: NASA's modern-era retrospective analysis for research and applications," Journal of Climate, vol. 24, no. 14, pp. 36243648, 2011.

[45] C. W. Landsea, C. Anderson, G. Clark et al., "The Atlantic hurricane database re-analysis project: documentation for the 1851-1910 alterations and additions to the HURDAT database," Hurricanes and Typhoons, pp. 177-221, 2004.

[46] P. A. Arkin and P. E. Ardanuy, "Estimating climatic-scale precipitation from space: a review," Journal of Climate, vol. 2, no. 11, pp. 1229-1238, 1989.

[47] B. Fontaine, S. Janicot, and V. Moron, "Rainfall anomaly patterns and wind field signals over West Africa in August (1958-1989)," Journal of Climate, vol. 8, no. 6, pp. 1503-1510, 1995.

[48] J. P. Grist and E. Nicholson, "A study of the dynamic factors influencing the rainfall variability in the West African Sahel," Journal of Climate, vol. 14, no. 7, pp. 1337-1359, 2001.

[49] P. Camberlin, S. Janicot, and I. Poccard, "Seasonality and atmospheric dynamics of the teleconnection between African rainfall and tropical sea-surface temperature: atlantic vs. ENSO," International Journal of Climatology, vol. 21, no. 8, pp. 973-1005, 2001.

[50] Chidong Zhang, "Large-scale variability of atmospheric deep convection in relation to sea surface temperature in the tropics," Journal of Climate, vol. 6, no. 10, pp. 1898-1913, 1993.

[51] J. P. Grist, S. E. Nicholson, and A. I. Barcilon, "Easterly waves over Africa. Part II: observed and modeled contrasts between wet and dry years," Monthly Weather Review, vol. 130, no. 2, pp. 212-225, 2002.
[52] C. D. Thorncroft and D. P. Rowell, "Interannual variability of African wave activity in a general circulation model," International Journal of Climatology, vol. 18, no. 12, pp. 13051323, 1998.

[53] J. G. Charney and M. E. Stern, "On the stability of internal baroclinic jets in a rotating atmosphere," Journal of the Atmospheric Sciences, vol. 19, no. 2, pp. 159-172, 1962.

[54] T. C. Chen, "Characteristics of African easterly waves depicted by ECMWF reanalyses for 1991-2000," Monthly Weather Review, vol. 134, no. 12, pp. 3539-3566, 2006.

[55] Chia-Bo Chang, "Impact of desert environment on the genesis of African wave disturbances," Journal of the Atmospheric Sciences, vol. 50, no. 14, pp. 2137-2145, 1993.

[56] R. J. Cornforth, B. J. Hoskins, and C. D. Thorncroft, "The impact of moist processes on the African Easterly JetAfrican Easterly Wave system," Quarterly Journal of the Royal Meteorological Society, vol. 135, no. 641, pp. 894-913, 2009.

[57] T. Lebel and A. Ali, "Recent trends in the Central and Western Sahel rainfall regime (1990-2007)," Journal of Hydrology, vol. 375, no. 1-2, pp. 52-64, 2009.

[58] S. E. Nicholson and I. M. Palao, "A re-evaluation of rainfall variability in the Sahel. Part I. Characteristics of rainfall fluctuations," International Journal of Climatology, vol. 13, no. 4, pp. 371-389, 1993.

[59] E. Mohino, S. Janicot, and J. Bader, "Sahel rainfall and decadal to multi-decadal sea surface temperature variability," Climate Dynamics, pp. 1-22, 2010.

[60] I. Pytharoulis and C. Thorncroft, "The low-level structure of African easterly waves in 1995," Monthly Weather Review, vol. 127, no. 10, pp. 2266-2280, 1999.

[61] Tsing-Chang Chen, "Global water vapor flux and maintenance during FGGE," Monthly Weather Review, vol. 113, no. 10, pp. 1801-1819, 1985.

[62] S. E. Nicholson, "A revised picture of the structure of the "monsoon" and land ITCZ over West Africa," Climate Dynamics, vol. 32, no. 7-8, pp. 1155-1171, 2009. 

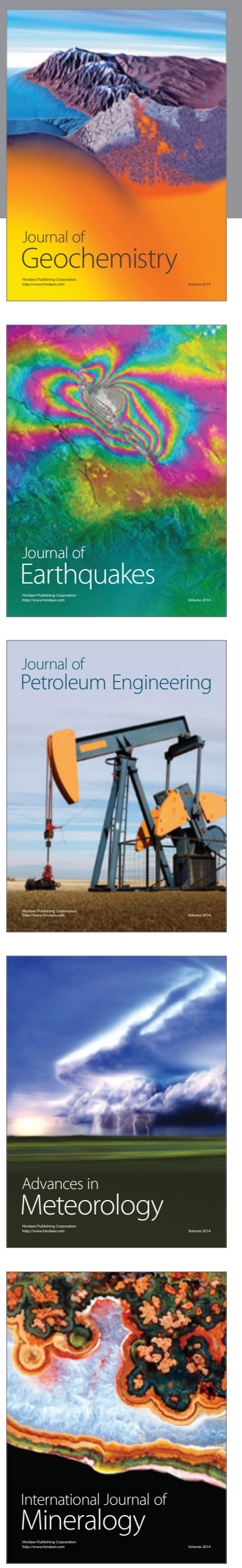
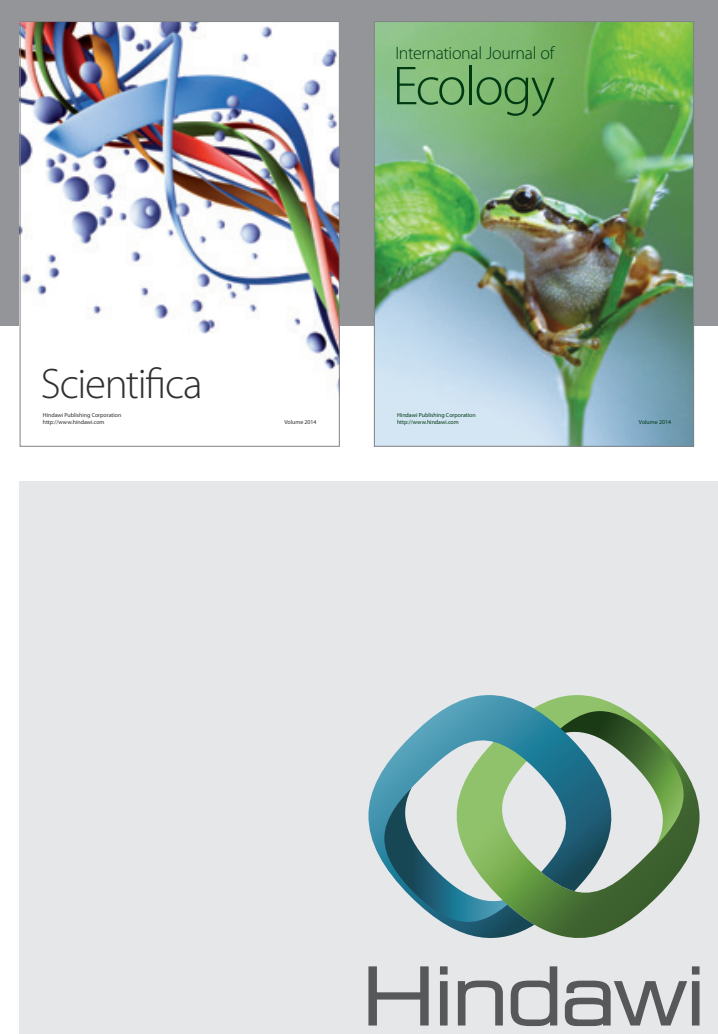

Submit your manuscripts at http://www.hindawi.com
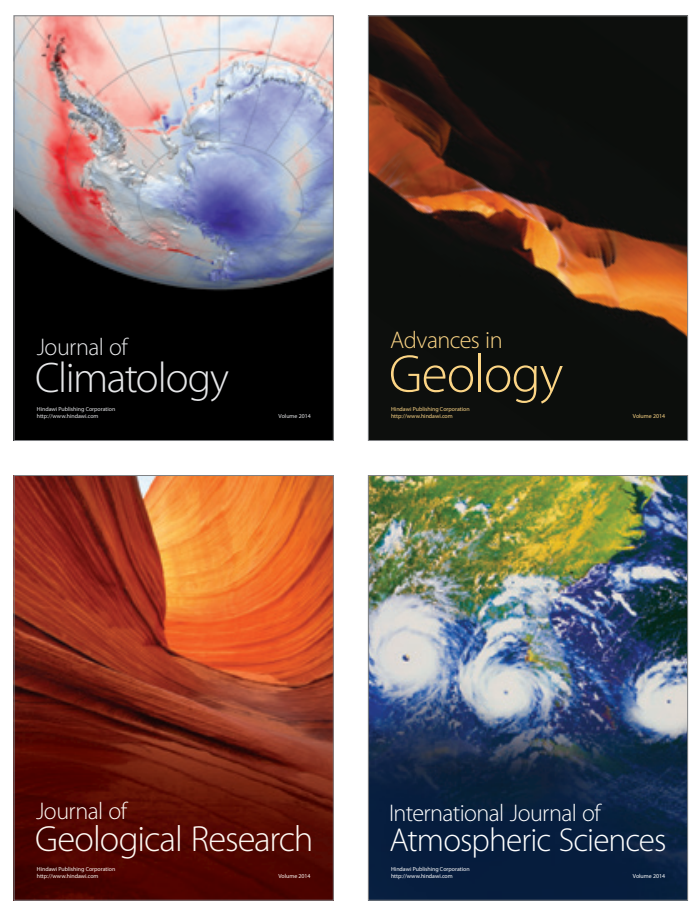
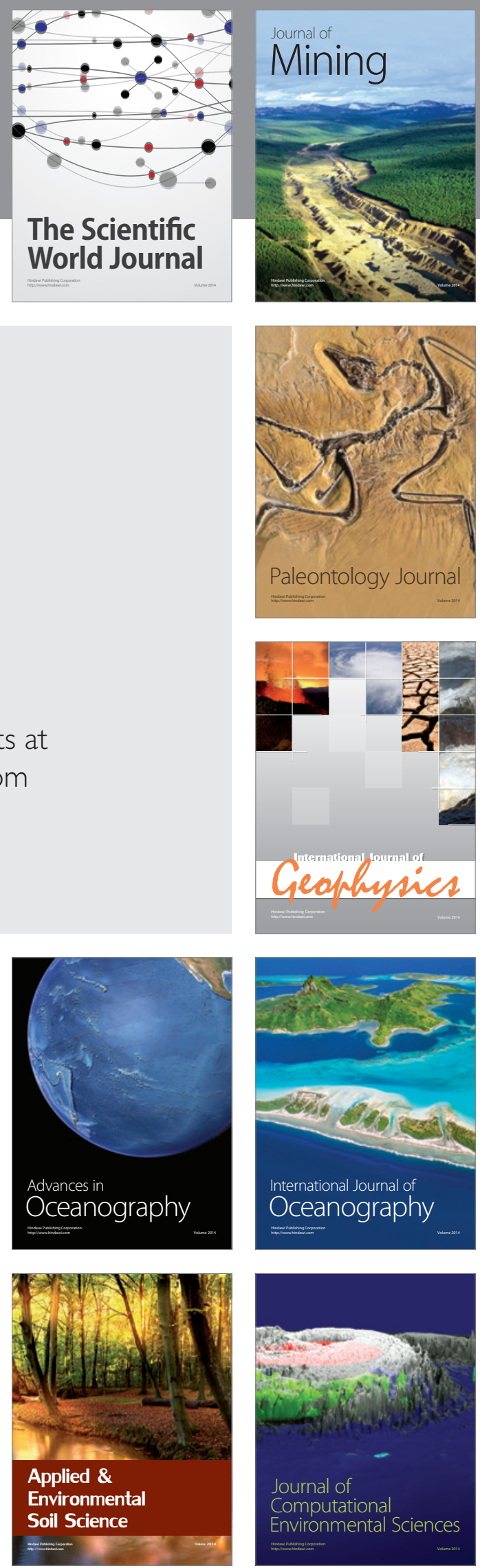